\title{
Impact of lenalidomide exposure on blood cell collection for autotransplants in persons with POEMS syndrome
}

Hao Cai, Jiefei Bai, Jian Li, Huacong Cai, Minghui Duan, Xinxin Cao, Miao Chen, Daobin Zhou, Wei Zhang

Department of Hematology, Peking Union Medical College Hospital, Chinese Academy of Medical Sciences and Peking Union Medical College, Beijing, China

Submitted: 5 December 2015

Accepted: 1 August 2016

Arch Med Sci 2018; 14, 5: 1048-1054

DOI: https://doi.org/10.5114/aoms.2016.63353

Copyright (c) 2016 Termedia \& Banach

\section{Abstract}

Introduction: Lenalidomide is an effective therapy of POEMS syndrome. However, there is concern that exposure to lenalidomide may reduce the efficiency of blood cell collection in persons who may eventually receive an autotransplant. We studied the impact of lenalidomide therapy on subsequent blood cell mobilization and collection including frequency of blood CD34+ cells and CXCR4 expression before and after mobilization with cyclophosphamide and granulocyte-colony stimulating factor (G-CSF).

Material and methods: Forty-three subjects with POEMS were assigned to receive lenalidomide and dexamethasone for $2-428$ d cycles $(n=19)$ or no therapy $(n=24)$. All subjects then received cyclophosphamide and G-CSF. Neither cohort had substantial numbers of blood CD34+ cells before mobilization.

Results: Mobilization increased blood CD34+ frequency in lenalidomidetreated subjects and controls similarly $(0.25 \%$ (95\% confidence interval $(\mathrm{Cl})$ : $0.03-1.39 \%$ vs. $0.32 \%, 0.04-1.47 \%), p=0.472)$. Increases in blood CD34+ numbers were also similar $\left(10 \times 10^{6} / \mathrm{l}\right)\left(5-77 \times 10^{6} / \mathrm{l}\right)$ vs. $14 \times 10^{6} / \mathrm{l}(6-101 \times$ $\left.10^{6} / \mathrm{l}\right), p=0.312$ ). Mean CXCR4 fluorescence intensity on bone marrow cells from controls decreased from $58 \pm 34$ (mean \pm SD) to $31 \pm 16$ after mobilization ( $p=\mathrm{NS}$ ). In contrast, mean CXCR4 intensity on bone marrow cells in lenalidomide-treated subjects increased from $55 \pm 43$ to $89 \pm 40$ ( $p=0.017$, comparing the deviation between two groups). Median numbers of CD34+ cells collected in lenalidomide-treated subjects and controls were $2.3 \times 10^{6} / \mathrm{kg}$ $\left(0.6-6.8 \times 10^{6} / \mathrm{kg}\right)$ and $2.810^{6} / \mathrm{kg}\left(1.0-8.9 \times 10^{6} / \mathrm{kg} ; p=0.521\right)$.

Conclusions: Brief lenalidomide treatment for POEMS did not reduce numbers of CD34+ blood cells collected but increased CXCR4 expression on bone marrow CD34+ cells.

Key words: POEMS syndrome, lenalidomide, blood cell collection, mobilization.

\section{Introduction}

POEMS syndrome is a rare plasma cell disorder, characterized by peripheral polyneuropathy, organomegaly, endocrinopathy, M-protein and skin changes. Associations with Castleman disease and osteopetrosis are also reported [1]. Although the etiology and pathogenesis of POEMS syndrome are unclear, vascular endothelial growth factor (VEGF) may be important [2]. There is no standard treatment for POEMS syndrome. High-dose melphalan followed by an autologous hematopoietic cell

\author{
Corresponding author: \\ Prof. Wei Zhang \\ Department of Hematology \\ Peking Union \\ Medical College Hospital \\ Chinese Academy \\ of Medical Sciences \\ and Peking Union \\ Medical College \\ No. 1 Shuaifuyuan \\ Beijing 100730, China \\ Phone: + 8613681473557 \\ E-mail: vv1223@vip.sina.com
}


transplant is effective [3-5], but it is sometimes difficult to obtain sufficient numbers of blood cells to perform an autotransplant [6].

Recently, lenalidomide was reported to be active in POEMS syndrome [7-10]. However, there is concern that lenalidomide therapy might worsen the problem of collecting adequate numbers of blood cells for a subsequent autotransplant [11-15]. For example, in persons with plasma cell myeloma, lenalidomide therapy is associated with less efficient blood cell collection of mobilization with granulocyte-colony stimulating factor (G-CSF) [11]. There are few data on the impact of lenalidomide therapy on blood cell mobilization and collection in persons with POEMS syndrome. We sought to answer this question by collecting blood cells from 43 subjects with POEMS treated or not treated with lenalidomide.

\section{Material and methods}

\section{Subjects}

We retrospectively report 43 consecutive subjects with POEMS syndrome seen at Peking Union Medical College Hospital between March, 2013 and March, 2014. Nineteen received 1-4 cycles of lenalidomide and dexamethasone. Twenty-four others received no therapy before apheresis. Both cohorts then received cyclophosphamide and G-CSF followed by apheresis to collect blood CD34+ cells. Subjects met diagnostic criteria for POEMS syndrome [16] including major (polyneuropathy and monoclonal plasma proliferative disorder) and $\geq 1$ minor criterion (bone lesions, Castleman disease, organomegaly, edema, endocrinopathy, skin changes and papilledema). The study was approved by the Institutional Review Board of Peking Union Medical College Hospital, and all subjects gave written informed consent.

\section{Lenalidomide cohort}

Subjects received 4 cycles of lenalidomide, 3 subjects received 3, 1 subject received $2,10 \mathrm{mg} /$ day orally, on days 1-21 and dexamethasone, $40 \mathrm{mg} /$ day orally on days $1,8,15$ and 22 of each 28 day therapy cycle. The total dosages of lenalidomide or dexamethasone for each subjects see Supplemental Table.

\section{Mobilization}

Cyclophosphamide, $2 \mathrm{~g} / \mathrm{m}^{2}$, given on day 0 followed by G-CSF, $300 \mu \mathrm{g}$ bid subcutaneously, on day 8 , was used to mobilize CD34+ cells into the blood on day 11 or 12 after cyclophosphamide subjects underwent apheresis using a Haemonetics multi-component collection system cell separator (Haemonetics Corporation, Braintree, MA). Subjects were evaluated for vascular access before apheresis to determine the best route of venous access. Blood was processed three times during each collection using citrate dextrose solution as an anticoagulant. Total nucleated cell numbers and CD34+ frequency were assayed. Blood CD34+ cells were first assayed on day 10 or 11 corresponding to 4 days after giving G-CSF. We then assayed CD34 cells daily until the apheresis procedure was completed. Bone marrow CD34 was first assayed the day before giving cyclophosphamide and then 9 to 10 days later, corresponding to 3 days after giving G-CSF. Subjects were termed poor mobilizers if $<1-2 \times$ $10^{6} / \mathrm{kg}$ CD34+ cells were collected from 1 mobilization procedure. Subjects who had $<1 \times 10^{6} / \mathrm{kg}$ CD34+ cells collected or had no collection were termed very poor mobilizers. Collections were typically successful in $\leq 3$ days in subjects with blood CD34+ level > $6 \times 10^{6}$ cells/l. We also performed bone marrow puncture to obtain the sample to analyze CXCR4 expression (Figure 1).

\section{Flow cytometry}

Before and after mobilization and apheresis, bone marrow cells were collected from 7 recipients of lenalidomide and dexamethasone and 9 subjects with no prior therapy. The number of CD34+ cells and CXCR4 expression on CD34+ cells were measured, and the frequency of blood CD34+ cells was determined by flow cytometry (BD FACSCalibur, USA). CD34+ cells were gated using the ISHAGE method. Specimens were analyzed using an internal control (IgG1a PE, IgG2k PE-CY7) and double test. Antibodies included: CXCR4 PECY7 Mouse Anti-Human Cat: 560669 BD, USA; Mouse IgG2a K, Isotype PE-CY7 Cat: 557907 BD, USA; CD45 PerCP Cat: 347464 BD, USA; IgG1 $\gamma 1$ PE Cat: 348057 BD, USA; CD34 8G12 PE Cat: 348057 BD, USA; BD FACS Lysing solution Cat: 349202 BD,

\begin{tabular}{|c|c|c|c|c|c|c|c|}
\hline CTX & Rest & & GCSF & $\begin{array}{l}\text { 1. GCSF } \\
\text { 2. Test blood CD34+ } \\
\text { 3. May apheresis }\end{array}$ & $\begin{array}{l}\text { 1. GCSF } \\
\text { 2. Test blood CD34+ } \\
\text { 3. May apheresis }\end{array}$ & $\begin{array}{l}\text { 1. GCSF } \\
\text { 2. Test blood CD34+ } \\
\text { 3. May apheresis }\end{array}$ & $\begin{array}{l}\text { 1. GCSF } \\
\text { 2. Test blood CD34+ } \\
\text { 3. If blood CD34+ } \\
\text { still less than } 6 \times 10^{6} / \text {, } \\
\text { mobilization is fail }\end{array}$ \\
\hline Day 1 Day 2 & & $\begin{array}{l}\text { Day } 7 \text { Day } 8 \\
\text { (GCSF day } 1\end{array}$ & $\begin{array}{c}\text { Day } 10 \\
\text { (GCSF day } 3)\end{array}$ & $\begin{array}{l}\text { Day } 11 \\
\text { 3) (GCSF day 4) }\end{array}$ & $\begin{array}{c}\text { Day } 12 \\
\text { (GCSF day 5) }\end{array}$ & $\begin{array}{c}\text { Day } 13 \\
\text { (GCSF day 6) }\end{array}$ & $\begin{array}{c}\text { Day } 14 \\
\text { (GCSF day 7) }\end{array}$ \\
\hline
\end{tabular}

Figure 1. Timeline of mobilization 
Table I. Pre-apheresis variables

\begin{tabular}{|c|c|c|}
\hline Parameter & $\begin{array}{l}\text { Controls } \\
(n=24)\end{array}$ & $\begin{array}{l}\text { Lenalidomide } \\
\qquad(n=19)\end{array}$ \\
\hline $\begin{array}{l}\text { Age, median (range) } \\
\text { [years] }\end{array}$ & $42(29-66)$ & $47(24-62)$ \\
\hline Male & 13 & 10 \\
\hline \multicolumn{3}{|l|}{ ONLS, median: } \\
\hline Upper & 2 & 1 \\
\hline Lower & 4 & 3 \\
\hline \multicolumn{3}{|l|}{ M-protein, $n(\%)$ : } \\
\hline $\lg A-\lambda$ & $13(54)$ & $8(42)$ \\
\hline $\operatorname{lgG}-\lambda$ & $7(29)$ & $9(47)$ \\
\hline Others & $4(17)$ & $2(11)$ \\
\hline Lymphadenopathy, $n$ (\%) & $16(67)$ & $12(63)$ \\
\hline Hepatomegaly, $n$ (\%) & $12(50)$ & $8(42)$ \\
\hline Splenomegaly, $n$ (\%) & $17(71)$ & $12(63)$ \\
\hline Edema, $n(\%)$ & $21(88)$ & $13(69)$ \\
\hline Ascites, $n(\%)$ & $11(46)$ & $7(37)$ \\
\hline $\mathrm{Ccr},<60 \mathrm{ml} / \mathrm{min}, n(\%)$ & $5(21)$ & $3(16)$ \\
\hline Serum VEGF [pg/ml] & 3865 & 1599 \\
\hline
\end{tabular}

USA. All antibodies were used according to the manufacturer's recommendations (fluorescent-labeled antibody was purchased from BD, USA).

CXCR4 expression on CD34+ cells was expressed as mean fluorescent intensity (MFI) on cells from bone marrow samples.

\section{Statistical analysis}

Student's $t$-test or Mann-Whitney $U$ test was used to compare continuous group variables. A $\chi^{2}$ test was applied for categorical data. Statistical tests used two-sided tests. Means and standard deviations were obtained with IBM
SPSS Statistics Version 19.0 software (SPSS Inc, Chicago, IL). $P$-values $<0.05$ were considered significant.

\section{Results}

\section{Subjects}

Forty-three consecutive subjects with POEMS syndrome were studied. Pre-apheresis variables are summarized in Table I. The schema describing patient treatment can be found in Figure 2 .

\section{Mobilization and apheresis}

Twenty-nine subjects were termed good mobilizers (CD34+ cells $\geq 2 \times 10^{6} / \mathrm{kg}$ ) including 12 subjects in the lenalidomide cohort and 17 in the control cohort. Eight subjects were termed poor mobilizers (CD34+ cells $1-2 \times 10^{6} / \mathrm{kg}$ ) including 4 subjects in each cohort. Six subjects were termed very poor mobilizers including 3 in each cohort. There was no significant difference in the distribution of types of mobilizers in the 2 cohorts (Table II).

Four subjects, 2 in each cohort, had no apheresis because of a low frequency of blood CD34+ cells $\left(<5 \times 10^{6} / \mathrm{l}\right)$ after cyclophosphamide and G-CSF. Thirty-nine subjects had apheresis. Lenalidomide-treated subjects and controls had similar frequencies of blood CD34+ cells $(0.25 \%, 95 \% \mathrm{Cl}$ : $0.03-1.39 \%$ vs. $0.32 \%, 0.04-1.47 \% ; p=0.472)$ and numbers of blood CD34+ cells $(10,5-77 \times$ $10^{6} / \mathrm{l}$ vs. $14,95 \% \mathrm{Cl}: 6-101 \times 10^{6} / \mathrm{l} ; p=0.312$ ). In lenalidomide-treated subjects, the number of CD34+ cells collected was 2.32 (95\% Cl: 0.6-6.8 $\left.\times 10^{6} / \mathrm{kg}\right)$, compared with $2.8\left(1.0-9 \times 10^{6} / \mathrm{kg}\right)$ in controls $(p=0.521$; Table II).

Table III shows the frequency of CD34+ cells and CXCR4 expression on bone marrow CD34+ cells before and after mobilization. Before mobilization bone marrow CD34+ frequency in both cohorts was similar $(0.93 \%, 0.38-2.04 \%$ vs. $1.1 \%$, $0.28-2.02 \% ; p=N S)$. After mobilization, frequency of CD34+ increased (Figure $3 \mathrm{~A}$ ) in both co-

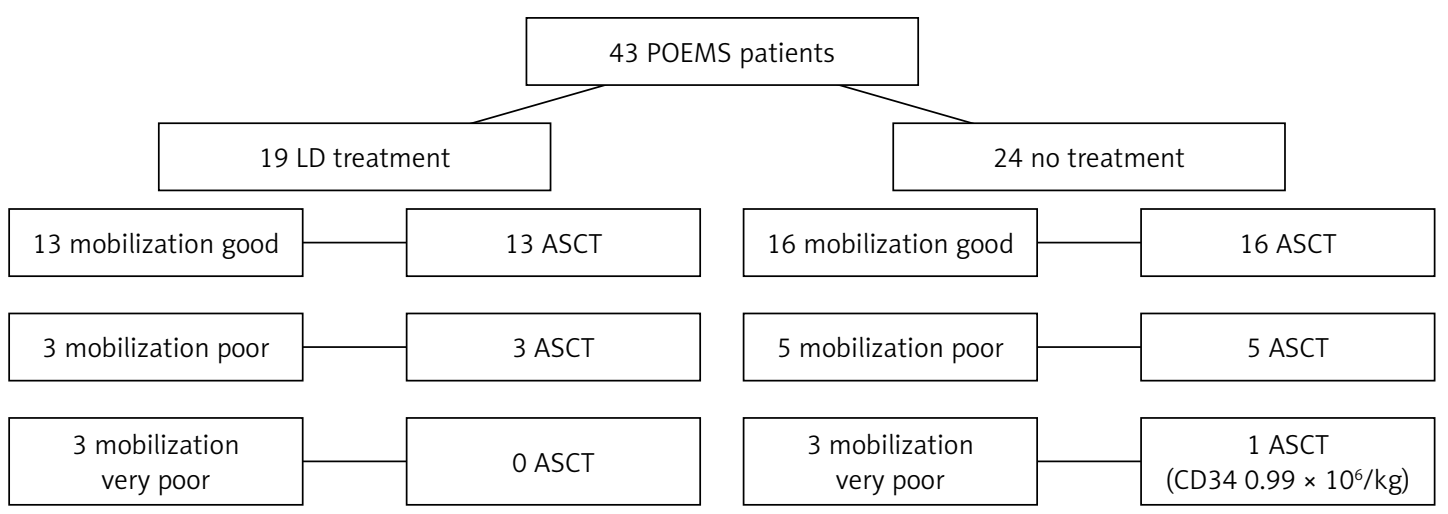

Figure 2. Schema describing patient treatment for the current study

$L D$ - lenalidomide and dexamethasone, ASCT - autologous peripheral blood stem cell transplant. 
Table II. Apheresis data

\begin{tabular}{|c|c|c|c|}
\hline Data & $\begin{array}{l}\text { Lenalidomide } \\
\qquad n=19\end{array}$ & $\begin{array}{c}\text { Controls } \\
n=24\end{array}$ & $P$-value \\
\hline Numbers of apheresis (median) & 2 & 2 & 0.621 \\
\hline Success numbers of apheresis: & 12 & 17 & 0.876 \\
\hline Good $\left(C D 34+\geq 2.0 \times 10^{6} / \mathrm{kg}\right)$ & $12(68 \%)$ & $17(71 \%)$ & NA \\
\hline Poor $\left(1.0<\mathrm{CD} 34+<2.0 \times 10^{6} / \mathrm{kg}\right)$ & $4(18 \%)$ & $4(17 \%)$ & NA \\
\hline Very poor $\left(\mathrm{CD} 34+\leq 1.0 \times 10^{6} / \mathrm{kg}\right)$ & $3(14 \%)$ & $3(13 \%)$ & NA \\
\hline Blood CD34+ frequency before mobilization (median) \% & NA & NA & NA \\
\hline Blood CD34+ frequency after mobilization, median $(95 \% \mathrm{Cl}) \%$ & $0.25(0.03-1.39)$ & $0.32(0.04-1.47)$ & 0.472 \\
\hline Blood CD34+ N after mobilization, median (95\% Cl) [10\%/l] & $10(5-77)$ & $14(6-101)$ & 0.312 \\
\hline Collected CD34+ PBSC, median $(95 \% \mathrm{CI})\left[10^{6} / \mathrm{kg}\right]$ & $2.32(0.6-6.8)$ & $2.8(1.0-9)$ & 0.521 \\
\hline
\end{tabular}

Table III. Percentage CD34 + cells and CXCR4 expression on bone marrow CD34+ cells before and after mobilization

\begin{tabular}{|lccc|}
\hline Data & $\begin{array}{c}\text { Lenalidomide } \\
n=7\end{array}$ & $\begin{array}{c}\text { Controls } \\
n=9\end{array}$ & $P$-value \\
\hline CD34+ of BM before mobilization, median $(95 \% \mathrm{Cl}) \%$ & $0.93(0.38-2.04)$ & $1.1(0.28-2.02)$ & 0.997 \\
\hline CD34+ of BM after mobilization, median $(95 \% \mathrm{Cl}) \%$ & $1.21(0.35-5.03)$ & $1.74(0.94-3.47)$ & 0.828 \\
\hline CXCR4 MFI before mobilization, mean \pm SD & $55.12 \pm 34$ & $58.43 \pm 43.43$ & 0.871 \\
\hline CXCR4 MFI after mobilization, mean \pm SD & $88.83 \pm 15.69$ & $31.09 \pm 39.84$ & 0.008 \\
\hline Change in CXCR4 MFI, mean \pm SD & $33.71 \pm 48.71$ & $-27.34 \pm 32.89$ & 0.017 \\
\hline
\end{tabular}

A

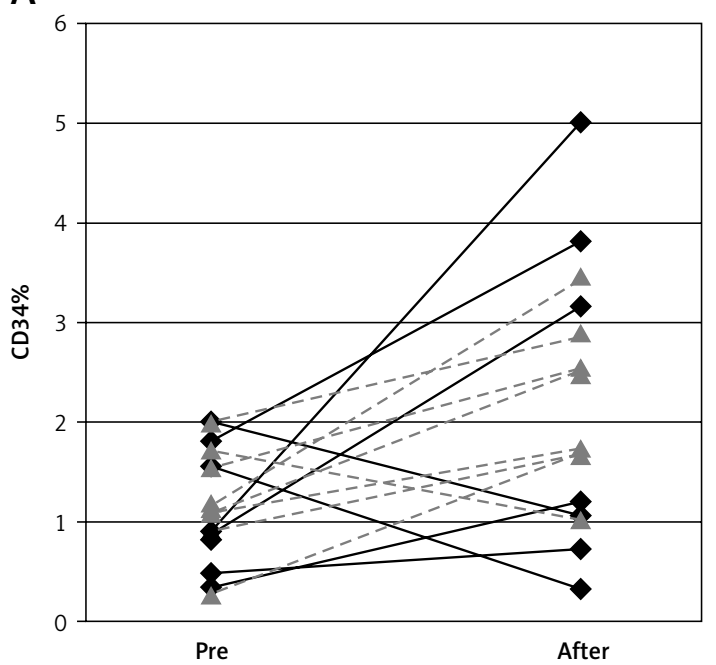

B

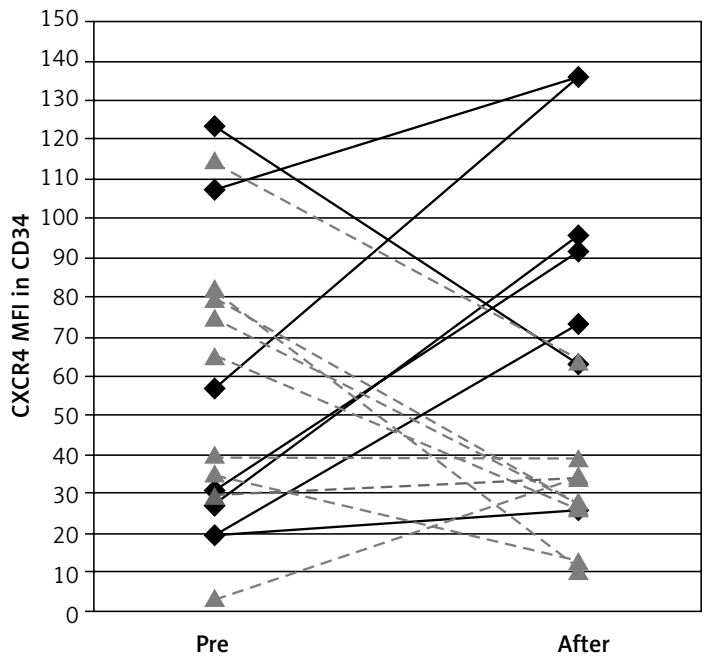

Figure 3. A - Change in percentage of CD34+ cells in 16 bone marrow specimens collected before and after mobilization, B - changes in CXCR4 mean fluorescent intensity on CD34+ cells collected before and after mobilization. Solid line represents LD-treated group; dashed line represents the untreated group

horts $(1.21 \%, 0.35-5.03 \%)$ in lenalidomide-treated subjects vs. $1.74 \%(0.94-3.47 \%)$ in controls $(p=0.828)$. After mobilization, mean fluorescent intensity of CXCR4 expression on CD34+ cells in controls decreased from $58 \pm 43$ to $31 \pm 40$, whereas in subjects receiving lenalidomide CXCR4 expression increased from $55 \pm 34$ to $89 \pm 16$ (Figure $3 \mathrm{~B} ; p=0.017$; Table III).

\section{Safety}

Three controls had fever and neutropenia after mobilization, 4 had severe edema, and 3 devel- 
oped acute renal failure. Two lenalidomide-treated subjects had fever and neutropenia and 1 had severe edema.

\section{Discussion}

Autotransplants are recognized as safe and effective therapy of POEMS syndrome [17]. We reported inability to collect sufficient numbers of CD34+ cells for an autotransplant in about one-half of subjects with newly diagnosed POEMS syndrome in 2013 [6]. Disease was correlated with poor mobilization. Recently, therapy with lenalidomide and dexamethasone was reported to be effective in POEMS syndrome $[9,10]$. However, some data suggest that extensive lenalidomide therapy decreases the likelihood of collecting sufficient numbers of CD34+ cells for an autotransplant [11, 12]. We analyzed data from 43 subjects with POEMS syndrome undergoing mobilization and apheresis, about onehalf of whom received $\leq 4$ cycles of lenalidomide and dexamethasone. We found no difference in the efficiency of mobilization and CD34+ cell collection compared with untreated controls. Interestingly, although CXCR4 expression on bone marrow CD34+ cells from lenalidomide-treated subjects was in creased, there was no impact on mobilization efficiency. There was also no increase in mobilization and apheresis in subjects receiving lenalidomide compared with controls.

LD treatment eliminated the inhibitory effect of adhesion factors after classic mobilization, and CXCR4 expression increased. In an in vitro study of lenalidomide on stem cell mobilization, Li et al. reported that lenalidomide did not damage bone marrow CD34+ hematopoietic stem cells, but significantly increased CXCR4 expression in CD34+ cells. Also, SDF-1 $\alpha$ mRNA did not increase [15]. So, lenalidomide did not induce bone marrow mesenchymal cell secretion of SDF-1 $\alpha$. Increased expression of CXCR4 after lenalidomide therapy may result from enhanced transportation of intracellular CXCR4 to the cell membrane with reduced internalization [15].

Mazumder et al. reported the impact of more than four cycles of lenalidomide on peripheral blood stem cell (PBSC) mobilization in multiple myeloma patients (70\% failed) [11]. But four or less cycles remained reliable (23\% failed) [10]. Like what we found in POEMS patients, less than 5 cycles of lenalidomide did not have an impact on mobilization efficiency, but also improved mobilization safety after treatment.

There are several limitations to our study. Subjects were assigned, not randomized to receive lenalidomide and dexamethasone vs. no therapy. Also, numbers of cycles of lenalidomide and dexamethasone were not prospectively specified. Nevertheless, we found no adverse impact of therapy with lenalidomide and dexamethasone on efficacy of CD34+ cell collection after mobilization. Our results should be validated in a randomized study.

Ghosh et al. reported that the influence of dexamethasone on the cell surface of CXCR4 can only last a few minutes [18]. So we can ignore the role of dexamethasone's effect on hematopoietic cell mobilization.

\section{Acknowledgments}

Hao Cai and Jiefei Bai contributed equally to this work.

Wang Xuan, Lian-Feng Chen and Jing-Chao Liu provided technical assistance. Professor Robert Peter Gale (Imperial College London) kindly reviewed and edited the typescript.

\section{Conflict of interest}

The authors declare no conflict of interest.

\section{References}

1. Dispenzieri A. POEMS syndrome. Blood Rev 2007; 21: 285-99.

2. D'Souza A, Hayman SR, Buadi F, et al. Utility of plasma vascular endothelial growth factor levels in the diagnosis and follow-up of patients with POEMS syndrome. Blood 2011; 118: 4663-5.

3. Dispenzieri A, Moreno-Aspitia A, Suarez GA, et al. Peripheral blood stem cell transplantation in 16 patients with POEMS syndrome, and a review of the literature. Blood 2004; 104: 3400-7.

4. Nakaseko C. Autologous stem cell transplantation for POEMS syndrome. Clin Lymphoma Myeloma Leuk 2014; 14: 21-3.

5. Xiong T, Chen X, Wei H, et al. Influence of PJ34 on the genotoxicity induced by melphalan in human multiple myeloma cells. Arch Med Sci 2015; 11: 301-6.

6. Li J, Zhang W, Duan MH, et al. PBSC mobilization in newly diagnosed patients with POEMS syndrome: outcomes and prognostic factors. Bone Marrow Transplantation 2013; 48: 233-7.

7. Lestang E, Caristan A, Neel A, et al. Lenalidomide as frontline therapy in POEMS syndrome: a retrospective case series of 8 patients. Leuk Lymphoma 2015; 56: 1895-6.

8. Semeraro $M$, Vacchelli E, Eggermont A, et al. Trial Watch: lenalidomide based immunochemotherapy. Oncoimmunology 2013; 2: e26494.

9. Royer B, Merlusca L, Abraham J, et al. Efficacy of lenalidomide in POEMS syndrome: a retrospective study of 20 patients. Am J Hematol 2013; 88: 207-12.

10. McDaniel JM, Pinilla-Ibarz J, Epling-Burnette PK. Molecular action of lenalidomide in lymphocytes and hematologic malignancies. Adv Hematol 2012; 2012: 513702.

11. Mazumder A, Kaufman J, Niesvizky R, Lonial S, Vesole D, Jagannath $\mathrm{S}$. Effect of lenalidomide therapy on mobilization of peripheral blood stem cells in previously untreated multiple myeloma patients. Leukemia 2008; 22: 1280-1.

12. Kumar S, Dispenzieri A, Lacy MQ, et al. Impact of lenalidomide therapy on stem cell mobilization and engraftment postperipheral blood stem cell transplantation 
in patients with newly diagnosed myeloma. Leukemia 2007; 21: 2035-42.

13. Pal R, Monaghan SA, Hassett AC, et al. Immunomodulatory derivatives induce PU.1 down-regulation, myeloid maturation arrest, and neutropenia. Blood 2010; 115: 605-14.

14. Koh KR, Janz M, Mapara MY, et al. Immunomodulatory derivative of thalidomide (IMiD CC-4047) induces a shift in lineage commitment by suppressing erythropoiesis and promoting myelopoiesis. Blood 2005; 105: 3833-40.

15. Li S, Fu J, Ma H, Mapara MY, Lentzsch S. Lenalidomide-induced upregulation of CXCR4 in CD34+ hematopoietic cells, a potential mechanism of decreased hematopoietic progenitor mobilization. Leukemia 2013; 27: 1407-11.

16. Dispenzieri A, Kyle RA, Lacy MQ, et al. POEMS syndrome: definitions and long-term outcome. Blood 2003; 101 2496-506.

17. Dispenzieri A. POEMS syndrome: 2014 update on diagnosis, risk-stratification, and management. Am J Hematol 2014; 89: 214-23.

18. Ghosh MC, Baatar D, Collins G, et al. Dexamethasone augments CXCR4-mediated signaling in resting human $T$ cells via the activation of the Src kinase Lck. Blood 2009; 113: 575-84. 
Supplemental Table

\begin{tabular}{|c|c|c|c|c|c|c|c|}
\hline Number & Gender & Age & CD34 & Mobilization & LD treatment & $\begin{array}{l}\text { Total dosages } \\
\text { of LEN [mg] }\end{array}$ & $\begin{array}{c}\text { Total dosages } \\
\text { of DEX [mg] }\end{array}$ \\
\hline 1 & M & 42 & 4.69 & Good & $4 \mathrm{LD}$ & 840 & 640 \\
\hline 2 & $M$ & 41 & 1.07 & Poor & 4 LD & 840 & 640 \\
\hline 3 & $\mathrm{~F}$ & 40 & 2.69 & Good & $\mathrm{N}$ & & \\
\hline 4 & M & 53 & 1.07 & Poor & $\mathrm{N}$ & & \\
\hline 5 & M & 63 & 1.89 & Poor & $\mathrm{N}$ & & \\
\hline 6 & M & 29 & 2.23 & Good & N & & \\
\hline 7 & M & 57 & 3.02 & Good & $\mathrm{N}$ & & \\
\hline 8 & $\mathrm{~F}$ & 35 & 8.85 & Good & $\mathrm{N}$ & & \\
\hline 9 & $\mathrm{~F}$ & 54 & 2.05 & Good & $\mathrm{N}$ & & \\
\hline 10 & M & 35 & 4.39 & Good & $4 \mathrm{LD}$ & 840 & 640 \\
\hline 11 & $\mathrm{~F}$ & 58 & 2.91 & Good & $4 \mathrm{LD}$ & 840 & 640 \\
\hline 12 & $\mathrm{~F}$ & 45 & 2.03 & Good & 4 LD & 840 & 640 \\
\hline 13 & M & 47 & 2.22 & Good & 4 LD & 840 & 640 \\
\hline 14 & M & 47 & 0 & Very poor & 4 LD & 840 & 640 \\
\hline 15 & M & 42 & 2.32 & Good & $4 \mathrm{LD}$ & 840 & 640 \\
\hline 16 & $\mathrm{~F}$ & 66 & 1.97 & Poor & $\mathrm{N}$ & & \\
\hline 17 & $\mathrm{~F}$ & 47 & 2.04 & Good & 4 LD & 840 & 640 \\
\hline 18 & $\mathrm{~F}$ & 62 & 0 & Very poor & $4 \mathrm{LD}$ & 840 & 640 \\
\hline 19 & $M$ & 46 & 1.93 & Poor & $4 \mathrm{LD}$ & 840 & 640 \\
\hline 20 & M & 53 & 1.61 & Poor & $N$ & & \\
\hline 21 & M & 51 & 0.99 & Very poor & $\mathrm{N}$ & & \\
\hline 22 & $\mathrm{~F}$ & 44 & 2.13 & Good & $\mathrm{N}$ & & \\
\hline 23 & M & 42 & 0 & Very poor & $\mathrm{N}$ & & \\
\hline 24 & $\mathrm{~F}$ & 42 & 2.22 & Good & $\mathrm{N}$ & & \\
\hline 25 & M & 42 & 3.69 & Good & $\mathrm{N}$ & & \\
\hline 26 & M & 53 & 3.08 & Good & $\mathrm{N}$ & & \\
\hline 27 & M & 48 & 2.39 & Good & 3 LD & 630 & 480 \\
\hline 28 & $M$ & 41 & 7.02 & Good & $\mathrm{N}$ & & \\
\hline 29 & $M$ & 39 & 4.11 & Good & $\mathrm{N}$ & & \\
\hline 30 & $\mathrm{~F}$ & 25 & 2.34 & Good & 3 LD & 630 & 480 \\
\hline 31 & $\mathrm{~F}$ & 35 & 6.77 & Good & $2 \mathrm{LD}$ & 420 & 320 \\
\hline 32 & $\mathrm{~F}$ & 51 & 3.69 & Good & $\mathrm{N}$ & & \\
\hline 33 & $\mathrm{~F}$ & 50 & 1.31 & Poor & $\mathrm{N}$ & & \\
\hline 34 & $\mathrm{~F}$ & 55 & 2.3 & Good & $4 \mathrm{LD}$ & 840 & 640 \\
\hline 35 & $M$ & 24 & 0.67 & Very poor & $4 \mathrm{LD}$ & 840 & 640 \\
\hline 36 & $\mathrm{~F}$ & 54 & 4.17 & Good & 3 LD & 630 & 480 \\
\hline 37 & $M$ & 29 & 0 & Very poor & $\mathrm{N}$ & & \\
\hline 38 & $M$ & 50 & 3.05 & Good & $\mathrm{N}$ & & \\
\hline 39 & $\mathrm{~F}$ & 49 & 3.84 & Good & $\mathrm{N}$ & & \\
\hline 40 & M & 58 & 2.91 & Good & $\mathrm{N}$ & & \\
\hline 41 & M & 30 & 1.96 & Poor & $4 \mathrm{LD}$ & 840 & 640 \\
\hline 42 & M & 35 & 4.44 & Good & $\mathrm{N}$ & & \\
\hline 43 & $M$ & 57 & 2.33 & Good & $4 \mathrm{LD}$ & 840 & 640 \\
\hline
\end{tabular}

